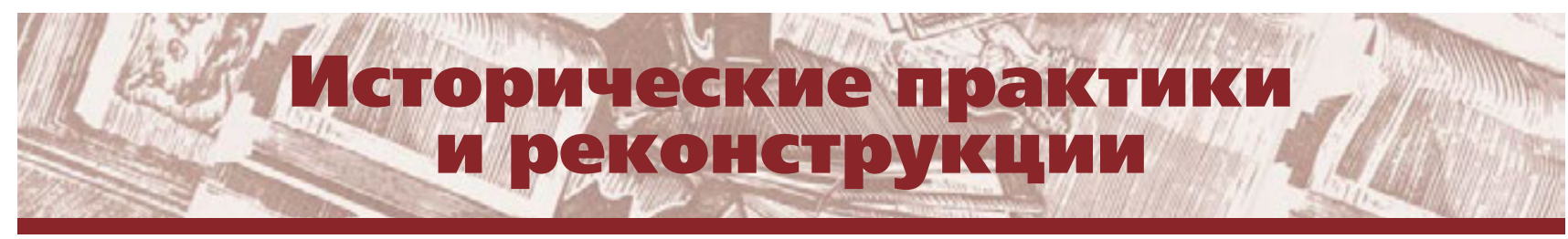

УДк 026.072(47)"188/191"

ББК $78.33(2) 53$

\title{
А.А. Соловьёв
}

\section{Библиотеки Костромской и Владимирской губернских ученых архивных комиссий (конец XIX - начало XX в.)}

Реферат. Рассматриваются малоисследованные библиотеки губернских ученых архивных комиссий (ГУАК) на примере Костромской и Владимирской губерний. Появившиеся в 1880-е гг. в Верхневолжье эти научные организации заметно обогатили местную книжную культуру и способствовали дальнейшему развитию библиотечного дела в регионе. Вокруг них объединялась местная интеллигенция, стоявшая у истоков создания первых научных библиотек на Верхней Волге. Благодаря деятельности ГУАК до нашего времени дошло большое количество письменных исторических источников. Подобные библиотеки спасли от уничтожения значительное число литературных памятников старины на территории Верхнего Поволжья, в том числе уникальных рукописей и старопечатных книг, сохранили научные исторические публикации.

Описывается книжно-библиотечная и просветительская деятельность Костромской ГУАК, начавшей свою работу в 1885 году. Раскрывается вклад Владимирской ГУАК, действовавшей с 1898 г., в развитие библиотечного дела Верхнего Поволжья. На основе печатных трудов и архивных материалов показана роль библиотек ГУАК по сохранению книжных памятников, ценных научных изданий и документов по истории Костромского и Владимирского краев. Некоторые материалы из библиотек Костромской и Владимирской ГУАК в наши дни сохранились в фондах Государственных архивов Костромской и Владимирской областей.

Ключевые слова: губернские ученые архивные комиссии, научная библиотека, Костромская губерния, Владимирская губерния, Верхнее Поволжье, краеведение, научные труды.

Для цитирования: Соловьёв A.А. Библиотеки Костромской и Владимирской губернских ученых архивных комиссий (конец XIX - начало XX в.) // Библиотековедение. 2017. Т. 66, № 2. С. 195 - 201.

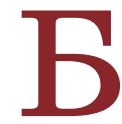
иблиотеки губернских ученых архивных комиссий (ГУАК) Верхнего Поволжья, (в настоящей статье - на примере Костромской и Владимирской губерний) находятся в основном вне поля научного интереса современных исследователей. Изучению подвергались главным образом научные библиотеки ГУАК Среднего Поволжья [1; 2], а на территории Верхневолжья авторы обращались прежде всего к народным и общественным публичным библиотекам [3-6].

Появление первых ГУАК было связано с попыткой проведения в Российской империи общей архивной реформы. Верхневолжский регион стал местом зарождения ГУАК. Первая подобная организация появилась в 1884 г. в Твери [7, c. 5]. Попечительство над ГУАК осуществляли

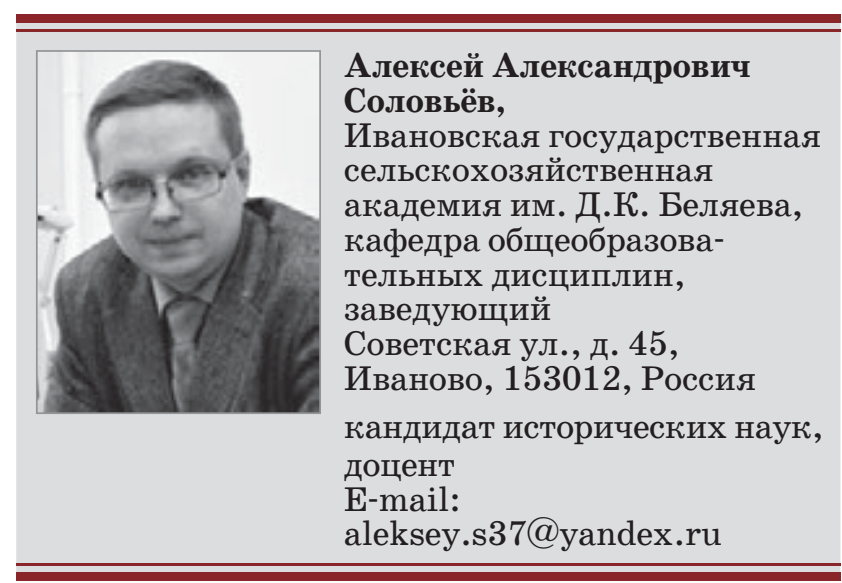




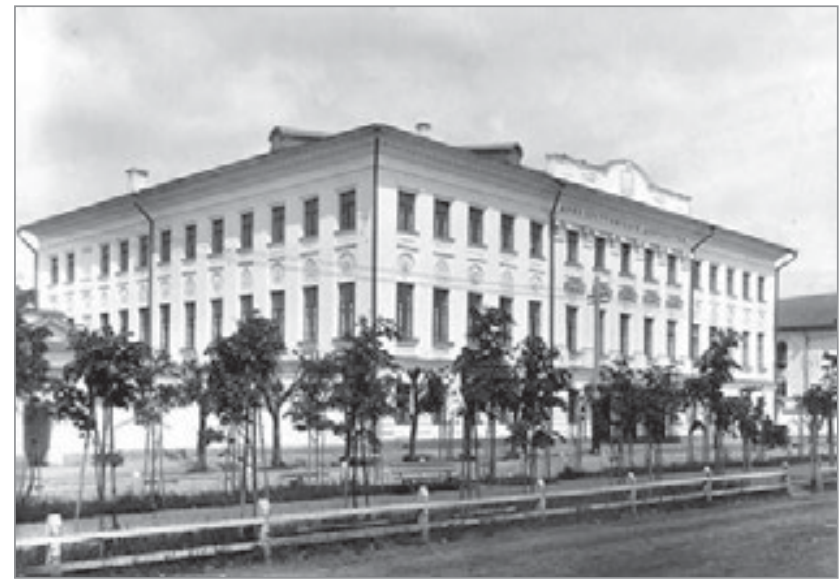

Здание Дворянского собрания, в котором размеща лась библиотека Костролской губернской ученой архивной комиссии до 1913 г. (фото начала XX в.)

губернаторы, научно-методическое руководство (до 1912 г.) - Петербургский археологический институт. Подчинялись они Министерству внутренних дел. Их средства складывались из членских взносов и частных пожертвований.

Главной задачей ГУАК являлся разбор ведомственных архивных документов и создание исторических архивов. В комиссии поступали также документы упраздненных учреждений, в том числе монастырских. Многие ГУАК проводили археологические раскопки, собирали этнографические и фольклорные материалы, помогали в реставрации архитектурных памятников, в организации выставок, экскурсий, лекций в музеях. Члены ГУАК активно участвовали во всероссийских историко-археологических съездах. На Верхней Волге прошли четыре областных съезда: в Ярославле (1901), Твери (1903), Владимире (1906) и Костроме (1909) [7, с. 21]. Большинство архивных комиссий издавали свои «Труды», «Известия» или «Сборники», включавшие публикации ценных рукописных памятников старины и краеведческие материалы. Многие из созданных российских провинциальных музеев появились благодаря стараниям членов ГУАК.

\section{Книжно-библиотечная и просветительская деятельность Костромской губернской ученой архивной комиссии}

Костромская губернская ученая архивная комиссия (КГУАК), начавшая свою работу в 1885 г., размещалась в нескольких комнатах здания Дворянского собрания на Павловской улице (ныне проспект Мира). В течение первых 12 лет ее возглавлял уроженец Костромской губернии, член Государственного совета, действительный тайный советник Н.Н. Селифонтов, юрист по образованию. Именно он стал одним из инициаторов создания специальной научной библиотеки при КГУАК. Обладая незаурядными организаторскими способностями, увле- каясь историей и археологией, он сделал немало для начала комплектования фондов библиотеки. После смерти Н.Н. Селифонтова (1900) по его завещанию в библиотеку КГУАК было передано 5 тыс. собранных им научных сочинений [8].

В первые годы своего существования библиотека имела весьма небольшой фонд и занимала две комнаты. В 1892 г. в ней насчитывалось чуть более 500 томов (без учета старопечатных книг). Пополнять библиотеку за свой счет мешал недостаточный бюджет КГУАК. Годовых субсидий комиссии в 500-800 руб. от Министерства юстиции и губернского земства явно не хватало [8]. Поэтому без частных пожертвований, безусловно, библиотека не могла бы нормально функционировать. Среди лиц, пожертвовавших наиболее ценные книжные собрания, следует назвать поэта Н.Ф. Грамматина (более 1600 томов), председателя Императорской археологической комиссии графа А.А. Бобринского, главу Комитета министров Н.Х. Бунге, костромского губернатора Л.М. Князева, директора народных училищ Костромской губернии И.П. Виноградова, профессора Московского университета М.И. Соколова [9].

Важной составляющей деятельности КГУАК был сбор рукописных книг и грамот, которые пополняли библиотеку и музей, особенное внимание уделялось выявлению и приобретению разнообразных источников по истории Костромского края в древности. Так, известный костромской библиофил Г.В. Юдин передал в библиотеку 150 экз., изданных им «Материалов для истории города Чухломы Костромской губернии». Епископ Костромской и Галицкий подарил «Сказание о явлении и чудесах иконы Федоровской Божьей Матери» [10].

Большое внимание архивная комиссия уделяла сбору данных об истории Дома Романовых. Был разработан план по нахождению материалов для воссоздания истории предков Михаила Федоровича Романова по материнской линии (его мать являлась уроженкой Костромского края). Неслучайно Н.Н. Селифонтов стал инициатором создания специального Романовского отдела при библиотеке и архиве КГУАК. Одной из ценнейших рукописей в библиотеке было предание о подвиге И. Сусанина, спасшего Михаила Романова от поляков. Н.Н. Селифонтов стал одним из инициаторов возведения памятника Ивану Сусанину в Костроме. В 1895 г. члены КГУАК начали активную подготовку к празднованию 300 -летия со дня рождения Михаила Федоровича Романова, исполнявшегося в 1896 году. Создание Романовского отдела библиотеки продолжалось вплоть до 1913 г. (год 300-летия царствования в России Дома Романовых). Комиссия сделала немало для ознакомления костромичей с историей предков Михаила Романова, опубликовала многие ценные рукописные источники. Однако апогеем всех праздничных мероприятий стало торжественное открытие 19 мая 1913 г. Романовского музея, созданного на 
основе музея древностей КГУАК, существовавшего с 1891 г. и насчитывающего много уникальных экспонатов [11].

Для музея построили специальное трехэтажное здание, на первом этаже которого разместилась научная библиотека и архив КГУАК. Хотя с 1907 г. музей, архив и библиотека занимали шесть комнат, этого было явно недостаточно. Новое помещение сразу же решило проблему нехватки площадей. Безусловно, без финансовой помощи частных лиц построить здание для Романовского музея было бы невозможно; следует назвать библиофила Г.В. Юдина, пожертвовавшего 10 тыс. руб. на его возведение [12]. Вот как описано открытие Романовского музея в журнале «Нива»: «Выстроенный на доброхотные пожертвования в стиле древних русских теремов, музей заключает в себе собрания редких и ценных предметов родной старины. В нижнем этаже помещаются архив и библиотека костромской архивной комиссии» [13].

КГУАК активно сотрудничала с другими подобными комиссиями и научными обществами. Они обменивались своими «Трудами», что значительно обогащало их библиотеки. Так, в библиотеку КГУАК свои издания присылали Императорское общество истории и древностей российских, Императорское Русское географическое общество, Историко-филологическое общество Казанского университета, а также архивные комиссии Ярославля, Владимира, Нижнего Новгорода, Твери, Орла, Рязани, Воронежа, Пензы, Оренбурга, Тамбова, Перми [14].

КГУАК также занималась активной научной деятельностью. Только при жизни своего первого председателя Н.Н. Селифонтова, члены комиссии издали 16 отдельных томов «Трудов» и четыре выпуска сборника «Костромская старина». В начале ХХ в. КГУАК в своих публикациях представляла очерки истории не только Костромы, но и уездных (Чухломы, Юрьевца, Ветлуги), а также заштатных городов (Плёса, Солигалича, Луха) и некоторых больших сел. Благодаря активной собирательской деятельности членов КГУАК, частным пожертвованиям, обмену литературой с научными организациями фонды библиотеки значительно увеличились и к 1917 г. вместе с архивными материалами составляли более 50 тыс. томов. В дальнейшем они стали основой документальной коллекции Костромского губернского архива.

Из наиболее крупных пожертвований в фонд библиотеки начала XX в. следует отметить передачу вдовой члена комиссии Н.М. Бекаревича большого количества книг из библиотеки мужа. Среди них значились весьма интересные издания: «Славяно-русская палеография» А.Н. Соболевского, «Древние памятники самозащиты и благочестия граждан Солигалича» И. Сырцова, «Речи И. Грозного на Земском соборе» С.Ф. Платонова, описание с. Парского Юрьевецкого уезда Костромской губернии и др. [15].

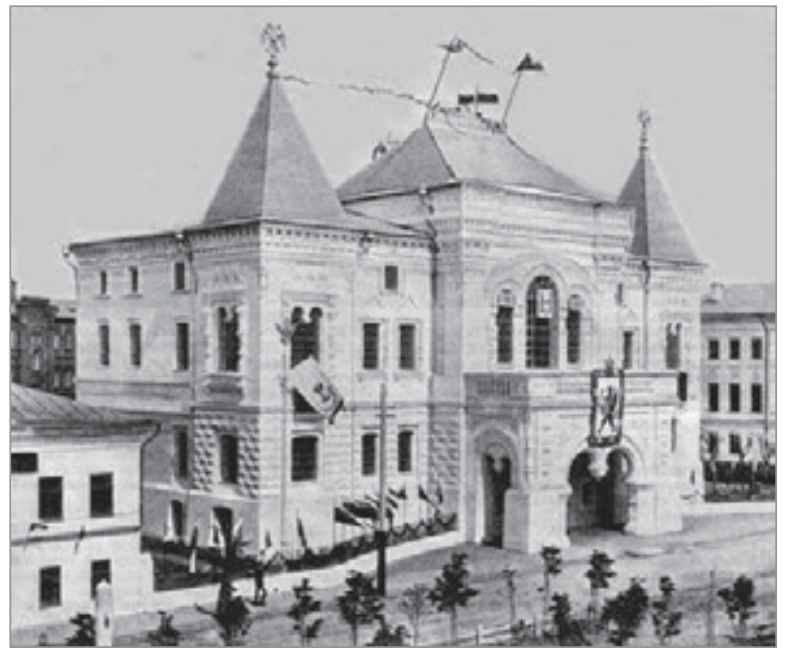

Здание Ролановского музея в Костроме, в которол размещалась библиотека Костролской губернской ученой архивной комиссии в 1913-1918 г2.

(фото начала $X X$ в.)

Научной библиотекой руководил совет КГУАК (П.А. Илинский, И.В. Баженов, С.Н. Романовский, И.М. Студицкий), а заведовал ею и являлся библиотекарем делопроизводитель комиссии. Долгое время эту должность занимал А.И. Черницын, который неоднократно жертвовал собственные книги, пополняя библиотечный фонд, он же составил каталоги всех рукописных и печатных сочинений. Библиотека предназначалась исключительно для научных целей, а пользоваться ее собраниями имели возможность только члены комиссии. В исключительных случаях те или иные сочинения могли быть выданы посторонним лицам, но обязательно по рекомендации кого-нибудь из состава КГУАК и разрешения совета комиссии. Книги выдавались на дом сроком до месяца. Библиотекарь следил, чтобы все рукописные документы и печатные издания возвращались неиспорченными. Особо строгому учету подлежали рукописи, грамоты и старинные свитки [16].

В 1918 г. КГУАК прекратила свое существование как самостоятельная организация. Она вошла в состав Костромского научного общества по изучению местного края в качестве его историкоархеологической секции.

\section{Вклад Владимирской губернской ученой архивной комиссии в развитие кникно- библиотечного дела Верхнето Поволжья}

Владимирская губернская ученая архивная комиссия (ВГУАК) появилась значительно позднее, чем аналогичная организация в Костроме, в 1898 году. Первым ее председателем стал владимирский вице-губернатор князь Н.П. Урусов, его заместителем - краевед, архивист и археолог А.В. Селиванов. Третьим человеком, стоявшим у истоков ВГУАК, был А.В. Смирнов - историк 


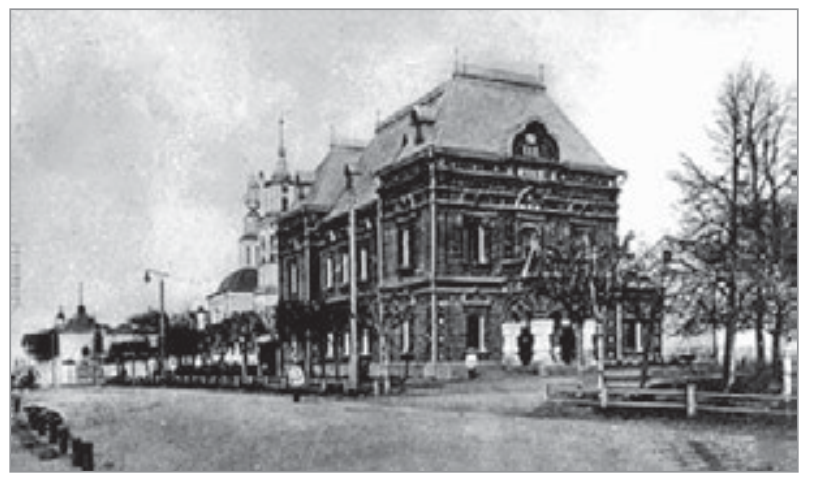

Здание Исторического музея, в котором размещалась библиотека Владимирской губернской ученой архивной колиссии в 1906-1918 г2. (фото начала XX в.)

русской литературы, краевед, археолог, археограф, библиограф [7, с. 11].

Благодаря усилиям этих трех людей во Владимире был возрожден губернский Исторический музей. В 1899 г. на Большой Московской улице для него начали строить просторное здание, часть его должны были занять созданные тогда же научная библиотека ВГУАК и архив. Денег на строительство музея катастрофически не хватало. Один из корреспондентов «Владимирских губернских ведомостей» недоуменно писал: «Нужно иметь слишком много любви к делу, преданности ему и светлой веры в будущее, чтобы решиться на такое важное дело, как устройство губернского музея, с теми скудными средствами, какими располагает ныне архивная комиссия» [17].

Действительно, первоначально на строительство здания музея и библиотеки члены ВГУАК смогли собрать всего около 8 тыс. руб., поэтому его возведение несколько затянулось. Однако благодаря частным пожертвованиям, особенно финансовой помощи местных фабрикантов, торжественное открытие Исторического музея состоялось 17 июня 1906 года. Прежде всего, следует отметить меценатскую помощь владельца хрустальных заводов Ю.С. Нечаева-Мальцова (кстати, благодаря его денежной поддержке в Москве был построен Музей изящных искусств им. императора Александра III, ныне - Государственный музей изобразительных искусств им. А.С. Пушкина). В одном из протоколов ВГУАК 1899 г. можно прочитать запись: «Имена всех жертвователей, внесших не менее 500 рублей на музей, должны быть внесены на мраморную доску во вновь построенном здании музея» [18, с. 12].

Открытие Исторического музея было приурочено к проведению во Владимире в июне 1906 г. III Областного историко-археологического съезда, который был организован одним из самых деятельных членов ВГУАК А.В. Селивановым. Он подарил библиотеке и музею ценные книги, предметы старины и быта.

Созданная в 1899 г. научная библиотека ВГУАК, первоначально насчитывала немногим более 1,3 тыс. книг и рукописей. Наиболее ценные дары в момент создания библиотеки сделала Императорская Академия наук, передавшая в ее фонд свыше 500 ценнейших изданий. Всего же в 1899-1900 гг. в библиотеку пожертвовали книги 39 научных обществ и учреждений Российской империи [18, с. 14].

К январю 1901 г. библиотека ВГУАК насчитывала уже более 5 тыс. томов научных сочинений и как нельзя лучше оправдывала цель своего создания - «в значительной степени служить пособием для желающих посвятить себя и свой досуг научным занятиям» [19]. Хотя доступ к фондам библиотеки имели только члены ВГУАК, в исключительных случаях поработать с книгами могли и посторонние лица, занимающиеся научной деятельностью.

Библиотека значительно пополнялась за счет частных пожертвований, которые за год часто превышали тысячу томов. Так, А.В. Смирнов подарил несколько тысяч ценных научных изданий, неоднократно передавал свои книги в фонд библиотеки и князь Н.П. Урусов. Определенные сочинения и рукописи специально приобретались на средства ВГУАК. Например, в 1900 г. была куплена интересная библиотека известного издателя и публициста из слободы Мстера Владимирской губернии И.А. Голышева [20].

Пополнялась библиотека и за счет научных трудов членов ВГУАК. Всего во Владимире увидели свет 18 крупных сборников и 39 отдельных публикаций, включавших в себя ценные рукописные материалы, которые стали доступны общественности [7, с. 11]. Естественно, большое место в деятельности комиссии занимала работа по поиску документов, касающихся истории Владимирского края. Автором интереснейших библиографических и краеведческих работ стал А.В. Смирнов, среди них следует назвать следующие труды: «Уроженцы и деятели Владимирской губернии, получившие известность на различных поприщах общественной пользы», «Материалы для истории Владимирской губернии», «Портретная галерея уроженцев и деятелей Владимирской губернии», «Опыт библиографического указателя о кустарной промышленности Владимирской губернии», «Труды Владимирской ученой архивной комиссии за первое десятилетие ее существования: 1899-1908. Библиографический указатель».

Фонд научной библиотеки ВГУАК быстро увеличивался. Так, в 1902 г. в нем насчитывалось свыше 8 тыс. томов, а в 1905 г. - более 14,3 тыс., поэтому перемещение библиотеки в здание губернского Исторического музея в 1906 г. было совершенно оправданным. В это время в ней состояло уже почти 16 тыс. томов (считая рукописи и старопечатные книги) [21-23]. В последующие годы библиотека развивалась весьма успешно, фонд регулярно пополнялся. Например, в 1910 г. он насчитывал более 18 тыс. томов, а в 
годы Первой мировой войны эта цифра составила уже более 20 тыс. книг и рукописей. Был создан систематический каталог всех имеющихся изданий, а библиотека разделена на два отдела - «рукописный» и «книжно-печатный» [24; 25].

ВГУАК прекратила свое существование в 1918 году. Здание, в котором находились Исторический музей, архив и библиотека, сохранилось. Сегодня в нем располагается экспозиция Владимиро-Суздальского музея-заповедника под названием «История Владимирского края», некоторые экспонаты которой были собраны членами архивной комиссии.

Следует отметить, что благодаря созданным учеными архивными комиссиями библиотекам, архивам и музеям-древлехранилищам, до нашего времени дошло большое количество письменных исторических источников. Члены ГУАК стали основоположниками научного краеведения, издавая научно-популярные работы, сохраняя культурное достояние России. Своими трудами они популяризировали историю той или иной губернии. Существовавшие при каждой архивной комиссии библиотеки по праву могут называться научными, исходя из состава их фондов. Библиотеки ГУАК Верхневолжья спасли от уничтожения немало литературных памятников старины (в том числе уникальных рукописей и старопечатных книг) и сохранили научные исторические публикации, многие из которых не потеряли своей актуальности и сегодня. Библиотеки, архивы, музеи ГУАК способствовали развитию научных исследований в российской провинции. Некоторые материалы из библиотек Костромской и Владимирской архивных комиссий в наши дни сохранились в фондах Государственных архивов Костромской и Владимирской областей.

\section{Список источников}

1. Валеев Э.Н. Научные библиотеки при губернских ученых архивных комиссиях // Библиотековедение. 2010. № 3. С. 99-105.

2. Курлаев М.В. Научные библиотеки губернских ученых архивных комиссий Среднего Поволжья // Научные и технические библиотеки. 2008. № 11. C. $48-56$.

3. Монякова O.A. Церковные и светские библиотеки российской провинции в середине XIX в. : (на материалах губерний Верхнего Поволжья) / / Библиотековедение. 2013. № 1. С. 104-109.

4. Соловьёв А.А. Общественные публичные библиотеки уездных городов Владимирской и Костромской губерний во второй половине XIX - начале XX века // Библиотековедение. 2010. № 5. С. 98-101.

5. Соловьёв А.А. Библиотеки городских обществ трезвости Владимирской и Костромской губерний в конце XIX - начале XX века / Библиотековедение. 2012. № 4. C. $102-107$.

6. Соловьёв А.А. Главная библиотека Иваново-Вознесенска: история создания и развития (1865-1917 гг.) // Библиотековедение. 2015. № 6. С. 92-97.
7. Макарихин В.П. Губернские архивные комиссии России. Нижний Новгород : Волго-Вятское кн. издво, 1991.118 с.

8. Государственный архив Костромской области. Ф. 179. Оп. 3. Д. 7. Л. 11-13.

9. Сапрыгина Е.В. Библиотека гуманитария // Костромская старина. 1998. № 10-11. С. 7.

10. Отчет о деятельности Костромской губернской ученой архивной комиссии за 1906 год. Кострома, 1908. С. 5.

11. Журнал заседания Костромской губернской ученой архивной комиссии от 18 мая 1895 года. Кострома, 1895. C. $2-4$.

12. Отчет о деятельности Костромской губернской ученой архивной комиссии за 1907 год. Кострома, 1908. C. $12-13$.

13. Открытие музея в Костроме // Нива. 1913. № 27. C. 527.

14. Отчет о деятельности Костромской губернской ученой архивной комиссии за 1904 год. Кострома, 1906. C. 16.

15. Журналы заседаний Костромской губернской ученой архивной комиссии за 1905, 1906, 1907, 1908 годы. Кострома, 1909. С. 71.

16. Отчет библиотеки // Костромская старина. Кострома, 1906. Т. 6. С. $34-35$.

17. Открытие губернского музея // Владимирские губернские ведомости (часть неофициальная). 1900. 29 мая. С. 4.

18. Отчет о деятельности Владимирской губернской ученой архивной комиссии за 1899 год // Труды Владимирской губернской ученой архивной комиссии. Владимир, 1900. Кн. II. С. 12-14.

19. Отчет о деятельности Владимирской губернской ученой архивной комиссии за 1900 год // Труды Владимирской губернской ученой архивной комиссии. Владимир, 1901. Кн. III. С. 23.

20. Отчет о деятельности Владимирской губернской ученой архивной комиссии за 1901 год // Труды Владимирской губернской ученой архивной комиссии. Владимир, 1902. Кн. IV. С. 15-16.

21. Отчет о деятельности Владимирской губернской ученой архивной комиссии за 1902 год // Труды Владимирской губернской ученой архивной комиссии. Владимир, 1903. Кн. V. С. 16.

22. Отчет о деятельности Владимирской губернской ученой архивной комиссии за 1905 год // Труды Владимирской губернской ученой архивной комиссии. Владимир, 1906. Кн. VIII. С. 16.

23. Отчет о деятельности Владимирской губернской ученой архивной комиссии за 1906 год // Труды Владимирской губернской ученой архивной комиссии. Владимир, 1908. Кн. IX. С. 17.

24. Отчет о деятельности Владимирской губернской ученой архивной комиссии за 1910 год // Труды Владимирской губернской ученой архивной комиссии. Владимир, 1911. Кн. ХII. С. 15.

25. Отчет о деятельности Владимирской губернской ученой архивной комиссии за 1914 год // Труды Владимирской губернской ученой архивной комиссии. Владимир, 1917. Кн. XVII. С. 12.

Иллюстративный материал предоставлен авторол статьи 


\title{
Libraries of Kostroma and Vladimir Provincial Scientific Archival Commissions in the late 19th - early 20th century
}

\author{
Alexey A. Soloviev, \\ Ivanovo State Agricultural Academy named after D.K. Belyaev, 45 Sovetskaya Str., Ivanovo, 153012, \\ Russia \\ E-mail: aleksey.s37@yandex.ru
}

\begin{abstract}
There are examined the underexplored libraries of the provincial scientific archival commissions at the example of Kostroma and Vladimir provinces. Appeared in the 1880-ies in the Upper Volga region, these research organizations - provincial scientific archival commissions (GUAC) - had significantly enriched the local book culture and contributed to the further development of librarianship in the region. The local intelligentsia, standing at the origins of the first scientific libraries in the Upper Volga Region, joined around these commissions. Thanks to the work of GUAC there had survived a great number of written historical sources. Such libraries had saved from destruction significant amount of literary monuments on the territory of the Upper Volga region, including unique manuscripts and early printed books, and had preserved historical and scientific publications.

There is described the library and educational activities of Kostroma GUAC, started its work in 1885 . There is revealed contribution of Vladimir GUAC, which operated since 1898, to the development of librarianship of the Upper Volga region. On the basis of the published works of commissions and archival materials there is shown the role of these libraries on preservation of the book monuments, valuable scientific editions and documents on the history of Kostroma and Vladimir land. Some of the materials from the libraries of Kostroma and Vladimir provincial scientific archival commissions nowadays are preserved in the collections of the State Archives of Kostroma and Vladimir regions.
\end{abstract}

Key words: Provincial Scientific Archival Commissions, Scientific Library, Kostroma Province, Vladimir Province, Upper Volga Region, Local History, Scientific Works.

Citation: Soloviev A.A. Libraries of Kostroma and Vladimir Provincial Scientific Archival Commissions in the late 19th - early 20th century, Bibliotekovedenie [Library and Information Science], 2017, vol. 66, no. 2 , pp. $195-201$.

\section{References}

1. Valeev E.N. Nauchnye biblioteki pri gubernskikh uchenykh arkhivnykh komissiyakh [Research Libraries to the Provincial Scientific Archival Commissions], Bibliotekovedenie [Library and Information Science], 2010, no. 3, pp. 99-105.

2. Kurmaev M.V. Nauchnye biblioteki gubernskikh uchenykh arkhivnykh komissii Srednego Povolzh'ya [Research Libraries of the Provincial Scholarly Archival Commissions in Mid-Volga Region], Nauchnye i tekhnicheskie biblioteki [Scientific and Technical Libraries], 2008, no. 11, pp. 48-56.

3. Monyakova O.A. Tserkovnye i svetskie biblioteki rossiiskoi provintsii v seredine XIX v.: (na materialakh gubernii Verkhnego Povolzh'ya) [Church and Secular Libraries of the Russian Province in the Middle of the 19 th Century (on the Materials of the Upper Volga Region Provinces)], Bibliotekovedenie [Library and Information Science], 2013, no. 1, pp. 104-109.

4. Soloviev A.A. Obshchestvennye publichnye biblioteki uezdnykh gorodov Vladimirskoi i Kostromskoi guber-

nii vo vtoroi polovine XIX - nachale XX veka [Public Libraries of the Vladimir and Kostroma Provinces' District Towns in the Second Half of the 19th - Early 20th Century], Bibliotekovedenie [Library and Information Science], 2010, no. 5, pp. 98-101.

5. Soloviev A.A. Biblioteki gorodskikh obshchestv trezvosti Vladimirskoi i Kostromskoi gubernii v kontse XIX - nachale XX veka [Libraries of City Sobriety Societies of the Vladimir and Kostroma Provinces in Late 19th - Early 20th Century], Bibliotekovedenie [Library and Information Science], 2012, no. 4, pp. 102-107.

6. Soloviev A.A. Glavnaya biblioteka Ivanovo-Voznesenska: istoriya sozdaniya i razvitiya (1865-1917 gg.) [The Main Library of Ivanovo-Voznesensk: the History of Creation and Development (1865-1917)], Bibliotekovedenie [Library and Information Science], 2015, no. 6, pp. 92-97.

7. Makarikhin V.P. Gubernskie arkhivnye komissii Rossii [Provincial Archival Commissions of Russia]. Nizhny Novgorod, Volgo-Vyatskoe Publ., 1991, 118 p. 
8. Gosudarstvennyi arkhiv Kostromskoi oblasti [The State Archive of the Kostroma Region], coll. 179, aids 3 , fol. 7 , pp. $11-13$.

9. Saprygina E.V. Biblioteka gumanitariya [Humanitarian's Library], Kostromskaya starina [The Old Kostroma], 1998, no. 10-11, p. 7.

10. Otchet o deyatel'nosti Kostromskoi gubernskoi uchenoi arkhivnoi komissii za 1906 god [The Report on the Activities of the Kostroma Provincial Scientific Archival Commission for 1906]. Kostroma, 1908, p. 5.

11. Zhurnal zasedaniya Kostromskoi gubernskoi uchenoi arkhivnoi komissii ot 18 maya 1895 god [The Journal of the Meeting of the Kostroma Provincial Scientific Archival Commission of 18 May 1895]. Kostroma, 1895, pp. 2-4.

12. Otchet o deyatel'nosti Kostromskoi gubernskoi uchenoi arkhivnoi komissii za 1907 god [The Report on the Activities of the Kostroma Provincial Scientific Archival Commission for 1907]. Kostroma, 1908, pp. 12-13.

13. Otkrytie muzeya v Kostrome [Opening of the Museum in Kostroma], Niva [Grainfield], 1913, no. 27, p. 527.

14. Otchet o deyatel'nosti Kostromskoi gubernskoi uchenoi arkhivnoi komissii za 1904 god [The Report on the Activities of the Kostroma Provincial Scientific Archival Commission for 1904]. Kostroma, 1906, p. 16.

15. Zhurnaly zasedanii Kostromskoi gubernskoi uchenoi arkhivnoi komissii za 1905, 1906, 1907, 1908 gody [The Journals of the Meetings of the Kostroma Provincial Scientific Archival Commission for 1905, 1906, 1907, 1908]. Kostroma, 1909, p. 71.

16. Otchet biblioteki [The Library Report], Kostromskaya starina [The Old Kostroma]. Kostroma, 1906, vol. 6, pp. $34-35$.

17. Otkrytie gubernskogo muzeya [Opening of the Provincial Museum], Vladimirskie gubernskie vedomosti (chast' neofitsial'naya) [The Vladimir Provincial Gazette (Unofficial Part)] 1900, 29 May, p. 4.

18. Otchet o deyatel'nosti Vladimirskoi gubernskoi uchenoi arkhivnoi komissii za 1899 god [The Report on the Activities of the Vladimir Provincial Scientific Archival Commission for 1899], Trudy Vladimirskoi gubernskoi uchenoi arkhivnoi komissii [The Works of the Vladimir Provincial Scientific Archival Commission]. Vladimir, 1900, book II, pp. 12-14.

19. Otchet o deyatel'nosti Vladimirskoi gubernskoi uchenoi arkhivnoi komissii za 1900 god [The Report on the Activities of the Vladimir Provincial Scientific Archival Commission for 1900], Trudy Vladimirskoi gubernskoi uchenoi arkhivnoi komissii [The Works of the Vladimir Provincial Scientific Archival Commission]. Vladimir, 1901, book III, p. 23.

20. Otchet o deyatel'nosti Vladimirskoi gubernskoi uchenoi arkhivnoi komissii za 1901 god [The Report on the Activities of the Vladimir Provincial Scientific Archival Commission for 1901], Trudy Vladimirskoi gubernskoi uchenoi arkhivnoi komissii [The Works of the Vladimir Provincial Scientific Archival Commission]. Vladimir, 1902, book IV, pp. 15-16.

21. Otchet o deyatel'nosti Vladimirskoi gubernskoi uchenoi arkhivnoi komissii za 1902 god [The Report on the Activities of the Vladimir Provincial Scientific Archival Commission for 1902], Trudy Vladimirskoi gubernskoi uchenoi arkhivnoi komissii [The Works of the Vladimir Provincial Scientific Archival Commission]. Vladimir, 1903, book V, p. 16.

22. Otchet o deyatel'nosti Vladimirskoi gubernskoi uchenoi arkhivnoi komissii za 1905 god [The Report on the Activities of the Vladimir Provincial Scientific Archival Commission for 1905], Trudy Vladimirskoi gubernskoi uchenoi arkhivnoi komissii [The Works of the Vladimir Provincial Scientific Archival Commission]. Vladimir, 1906, book VIII, p. 16.

23. Otchet o deyatel'nosti Vladimirskoi gubernskoi uchenoi arkhivnoi komissii za 1906 god [The Report on the Activities of the Vladimir Provincial Scientific Archival Commission for 1906], Trudy Vladimirskoi gubernskoi uchenoi arkhivnoi komissii [The Works of the Vladimir Provincial Scientific Archival Commission]. Vladimir, 1908, book IX, p. 17.

24. Otchet o deyatel'nosti Vladimirskoi gubernskoi uchenoi arkhivnoi komissii za 1910 god [The Report on the Activities of the Vladimir Provincial Scientific Archival Commission for 1910], Trudy Vladimirskoi gubernskoi uchenoi arkhivnoi komissii [The Works of the Vladimir Provincial Scientific Archival Commission]. Vladimir, 1911, book XII, p. 15.

25. Otchet o deyatel'nosti Vladimirskoi gubernskoi uchenoi arkhivnoi komissii za 1914 god [The Report on the Activities of the Vladimir Provincial Scientific Archival Commission for 1914], Trudy Vladimirskoi gubernskoi uchenoi arkhivnoi komissii [The Works of the Vladimir Provincial Scientific Archival Commission]. Vladimir, 1917, book XVII, p. 12. 